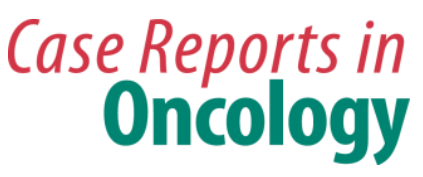

Case Rep Oncol 2017;10:832-839

DOI: $10.1159 / 000478846$

Publisned online: september 15, 2017
(C) 2017 The Author(s)

Published by S. Karger AG, Basel

www.karger.com/cro

This article is licensed under the Creative Commons Attribution-NonCommercial 4.0 International License (CC BY-NC) (http://www.karger.com/Services/OpenAccessLicense).

Usage and distribution for commercial purposes requires written permission.

\title{
An Uncommon Presentation of a Metachronous Testicular Primary Nonseminoma and Seminoma Separated by Two Decades and a Testicular Cancer Literature Review
}

\author{
Dennis Andrew Buck ${ }^{a} \quad$ Tristan Dean Smith $^{\mathrm{b}} \quad$ Wilbur Nelson Montana ${ }^{\mathrm{a}}$ \\ ${ }^{a}$ Cancer Treatment Centers of America, Southwestern Regional Center, Tulsa, OK, USA; \\ ${ }^{b}$ Oklahoma State University, College of Osteopathic Medicine, Tulsa, OK, USA
}

\section{Keywords}

Seminoma $\cdot$ Contralateral metachronous testicular cancer $\cdot$ Second primary testicular cancer

\begin{abstract}
Introduction: Testicular cancer is the most common malignancy in men aged 15-40 years [Bols et al.: Philadelphia, Wolters Kluwer, Lippincott Williams \& Wilkins, 2011]. Its incidence comprises $0.8 \%$ of all male cancers worldwide, with a mortality rate of $0.1 \%$. The incidence has nearly doubled from 1975 to 2007 leading to the concern of environmental causes [Thomas: Am J Epidemiol 2013;178:1240-1245]. Testicular cancer presents as a painless testicular mass without transillumination. Testicular cancer is subcategorized under germ cell testicular cancer or sex cord-stromal tumors. Of the germ cell tumors, approximately $90 \%$ originate in the testis, with the other $10 \%$ being extragonadal [Bols et al.: Philadelphia, Wolters Kluwer, Lippincott Williams \& Wilkins, 2011]. Typically, if a patient presents with a testicular mass and is 50 years old or older, the diagnosis of a primary lymphoma is considered until proven otherwise [Bols et al.: Philadelphia, Wolters Kluwer, Lippincott Williams \& Wilkins, 2011]. Germ cell testicular cancer is further divided into the subtypes of seminomatous and nonseminomatous; each presents with a unique histology and differing treatment implications. Discussion: Given the uniqueness of our patient's metachronous second testicular primary, we sought to compare our case findings to available historic publications. We
\end{abstract}




\section{Case Reports in Oncology}

sought to address the issues of the incidence of a second primary testicular malignancy with regard to varying histology, age of incidence, and timing of a second primary testicular cancer, the presence of bowel involvement, and finally a brief discussion of testosterone replacement therapy. Conclusion: A review of our case presents several unique factors. The above varying literature has shown our patient to have met the odds of a contralateral testicular primary development in that he had a nonseminomatous primary, followed by a second testicular primary seminoma. Our patient exceeded the 15-year cumulative risk of contralateral metachronous testicular cancer of $1.9 \%$ versus the seemingly contradictory $5.2 \%$ cumulative risk 25 years after the first testicular germ cell tumor. With his second primary (seminoma), he presented with the common retroperitoneal landing zone site, though with an uncommon involvement of the gastrointestinal tract $(<1 \%)$ and rare incidence of involving the duodenum.

(C) 2017 The Author(s)

Published by S. Karger AG, Basel

\section{Case Report}

A 50-year-old Caucasian male presented to our clinic in 2016 following a recent referral by his primary care physician to gastroenterology for a new diagnosis of iron deficiency anemia. A jejunal mass biopsy identified a classic seminoma (negative $\alpha$-fetoprotein, with elevated lactate dehydrogenase and $\beta$-human chorionic gonadotropin).

CT of the chest, abdomen and pelvis identified a $13.4 \times 13.2 \mathrm{~cm}$ retroperitoneal mass circumferentially involving the infrarenal aorta, inferior mesenteric artery, and the 3rd portion of the duodenum, and a mass effect on the inferior vena cava and right ureter with subsequent right hydronephrosis. Further retroperitoneal mesenteric nodules were seen and a right ureteral stent was placed (Fig. 1a-c).

A CT-guided retroperitoneal mass biopsy confirmed a metastatic germ cell tumor consistent with classical seminoma (negative CD45; PLAP and keratin AE1/3 positive). A pretreatment PET scan confirmed a solitary hypermetabolic right testicle with mass, a large hypermetabolic retroperitoneum/para-aortic mass, with a lower anterior abdomen and pelvic stranding with hypermetabolism consistent with carcinomatosis (Fig. 2a-c). Right orchiectomy confirmed a 2.3-cm classic seminoma (pT1NX; CD117 negative).

Interestingly, our patient had a remote history of stage IIIA nonseminomatous left testicular cancer diagnosed in 1994. Radical left orchiectomy confirmed a nonseminomatous immature teratoma with embryonal elements; postoperative elevated $\alpha$-fetoprotein persisted. Months later (by late 1994), chest imaging identified a right upper lobe lung lesion, which a nonseminomatous malignancy on biopsy. A right upper lung wedge resection performed in early 1995 confirmed a mixed germ cell tumor with teratomatous elements. By late 1995, the patient received an unconfirmed regimen of adjuvant chemotherapy (all while under the service of a prior oncology facility). By 2016, nearly all prior evidence of medical records had been purged and only fragments were available.

Thus, 22 years since his diagnosis of first testicular primary (left-sided nonseminomatous testicular cancer), he presented to our clinic with a new diagnosis of a second testicular primary, i.e., a right-sided testicular stage IIIC (S1) classical seminoma ( $\alpha$-fetoprotein negative, intermediate risk, with a bulky retroperitoneal mass encompassing the infrarenal aorta, inferior mesenteric artery, and small bowel invasion).

Our patient was provided four cycles of cisplatin and etoposide. Restaging CT showed a significant retroperitoneal mass treatment effect (now measuring $6.4 \times 3.6 \mathrm{~cm}$ ), and complete radiographic resolution of peritoneal carcinomatosis. PET imaging, performed more 
than 6 weeks from the last dose of chemotherapy (Fig. 3a-c), identified a 3.7-cm retroperitoneal mass with residual increased glycolytic activity of a standard uptake value of $2.8 \mathrm{~g} / \mathrm{dL}$. An unsuccessful endoscopic ultrasound-attempted biopsy was made at the residual mass by gastroenterology, interventional radiology was also unable to safely biopsy, and surgical oncology identified the patient as a nonsurgical case due to vascular involvement. Restaging PET performed 8 weeks (Fig. $4 \mathrm{a}-\mathrm{c}$ ) later identified stable size with a standard uptake value of $2.6 \mathrm{~g} / \mathrm{dL}$. Due to seminomas being extremely radiosensitive [1-4], we referred the patient to radiation oncology. They favored close active surveillance, with which the patient concurred.

\section{Literature Review and Discussion}

In review of our patient's unique metachronous presentation, several questions arise. Further investigation was taken to evaluate the likelihood and incidence of similar findings found amongst historical publications. We sought to address the issues of the incidence of a second primary testicular malignancy with regard to varying histology, age of incidence, timing of the second primary, the presence of bowel involvement, and finally a brief discussion of testosterone replacement therapy (TRT).

Patients presenting with a unilateral testicular tumor are at risk for developing a contralateral tumor with the same or a different histology. Thus, a metachronous germ cell tumor is likely to occur in a contralateral testis in $2-3 \%$ of all testicular germ cell tumor patients [4]. A study in Denmark found that the incidence of a second primary testicular germ cell tumor among men with a histologically verified first primary germ cell tumor diagnosed between 1960 and 1979 was $2.6 \%$ [5]. The cumulative risk of developing a contralateral cancer 25 years after the diagnosis of the first testicular germ cell cancer was $5.2 \%$ according to the Kaplan-Meier estimate. It was higher among men with a nonseminoma as the first tumor $(8.4 \%)$ than among men with a seminoma as the first tumor (3.6\%). Of the second tumors, $12 \%$ were stage II and $17 \%$ were stage III at the time of diagnosis [5]. The overall relative risk (RR) of developing a second primary cancer in the contralateral testicle following a first germ cell cancer was found to be 24.8 (95\% confidence interval). Among men with a nonseminoma, the risk was higher $(\mathrm{RR}=27.1)$ than among men with a seminoma $(\mathrm{RR}=$ 22.5) [5].

According to the National Cancer Institute and Surveillance, Epidemiology and End Results (SEER) program, between 1973 and 2001, there were some 29,515 men under 55 years old with testicular cancer. At presentation, 175 men had a synchronous testicular cancer $(0.6 \%)$. In this study, the 15-year cumulative risk of contralateral (metachronous) testicular cancer was $1.9 \%$ [6]. This increased risk of developing a contralateral testicular tumor has been described in the literature as having a low incidence [7], though also as having a 500- to 1,000-fold increased risk [8,9], as well as a 12- to 124-fold likelihood compared to unaffected men of the same age, race, and ethnicity to develop a first primary testicular germ cell tumor [10], whereas a metachronous germ cell tumor may present in the contralateral testicle in approximately $2-5 \%$ of all testicular germ cell tumor patients $[4,11]$.

Thomas' [10] study showed that the mean ages at the diagnosis of the first and second testicular germ cell tumor have been reported to be 31.2 and 35.6 years, respectively. Seminomas comprised $61.1 \%$ of first primary and $70.5 \%$ of second primary testicular germ cell tumors. Men for whom the first primary testicular germ cell tumor was a seminoma tended to be older at the time of the first diagnosis than those whose first testicular germ cell tumor 


\section{Case Reports in Oncology}

was a nonseminoma (mean age at first diagnosis: 33.8 vs. 27.3 years). Within each of these groups, the age at diagnosis of the second testicular germ cell tumor tended to be higher for those whose second testicular germ cell tumor was a seminoma [10]. Contralateral testicular tumors have been reported to be diagnosed as late as 20-30 years following the diagnosis of the first testicular tumor [7].

These above statistics refer to a second primary, as opposed to a relapse or recurrence. The diagnosis of a second primary was a clear finding in our patient due to a differing histology, whereas among those patients who relapse most will manifest disease within 2 years following the initial diagnosis. Late relapses have been reported and may occur as late as 30 years after the original diagnosis $[7,12]$. Such a late relapse is extremely rare. Oldenburg et al. $[13,14]$ from Norway found the cumulative 10 -year late relapse rate to be $1.3 \%$.

A review of the literature may yield some stark contrasts, as Thomas [10] identified that amongst men with bilateral testicular germ cell tumors there was no association identified between the histology of the first and second testicular germ cell tumors. These results were then held by such authors to lend credence to an alternate possibility that exposures underlying both subtypes of germ cell tumors occur early in development. Interestingly, an emerging topic that has brought on much speculation and is met with increasing usage within the last several generations of North America and Europe is marijuana use. Marijuana, considered an environmental exposure common in the peripubertal and early adult period, has been reported to be specifically associated with a nonseminoma risk [10].

Approximately one half of patients with nonseminomatous germ cell tumors present at stage IV $[15,16]$. Generally, these tumors metastasize to the landing zone retroperitoneal lymph nodes and, less commonly, to the lungs, liver, and the brain. Gastrointestinal metastases are very rare and may present with bowel obstruction or, less frequently, with hemorrhage $[15,17]$.

According to Chait et al. [18] in a study performed to evaluate the origin of malignant metastases spreading to the gastrointestinal tract, bowel metastases occur in $5 \%$ of all patients diagnosed with germ cell tumor of the testicle. Involvement of the duodenum was seen in only 7 cases. Embryonal carcinoma was the dominant component found on pathology in all cases that had metastasized to the bowel, whereas a pure seminoma will metastasize to the gastrointestinal tract in less than $1 \%$ of cases (also a poor prognostic factor), and typically by direct invasion from the retroperitoneal lymph nodes which drain the testis $[8,19]$, with the duodenum being the least common location for a gastrointestinal tract metastasis $[8,9]$.

These cases of pure seminomas with M1 disease affecting the gastrointestinal tract have been found to have a lower response to systemic chemotherapy (60\%), compared to pure seminoma without metastasis (90\%) [20]. According to Senadhi and Dutta [9], among gastrointestinal sites the duodenum is the least common site involved.

In an age of public concern over risks of hormone replacement therapy, an authority such as Cancer: Principles and Practice of Oncology [4] confirms that any man with bilateral orchiectomy should be on testosterone replacement. In a study performed by Chia et al. [21], which evaluated serum testosterone concentrations and the risk of testicular germ cell tumors, there were no overall statistically significant associations between sex hormonebinding globulin and total testosterone concentrations and testicular germ cell cancer risks. This reinforces the idea that serum testosterone is not associated with risk of a testicular germ cell malignancy. There appears to be a lack of literature confirming the suspicion of correlation between TRT and testicular cancer risks, though some literature attempt to con- 


\section{Case Reports in Oncology}

nect muscle building supplements such as androstenedione and creatine to increasing risks and incidence of testicular cancer [22].

Testicular cancer treatment has been found to decrease fertility in $50 \%$ of patients. This is due in part to the irreversible nature of treatment-related impaired spermatogenesis in a contralateral testis (occurring in $94 \%$ of patients) [23]. A study performed by Lackner et al. [24] showed that almost half (47\%) of testicular cancer survivors experienced clinical symptoms of androgen deficiency, $28.9 \%$ had erectile dysfunction, and $25.3 \%$ had laboratoryproven hypogonadism. The most common sequelae in long-term survivors of testicular cancer are fertility complications, endocrine disturbances, and sexual dysfunction. These results support evidence that testicular cancer survivors experience a high level of clinical symptoms of hypogonadism despite a relatively low prevalence of laboratory hypogonadism. A study by Oree et al. [25] found the prevalence of chronic fatigue syndrome in testicular cancer to be $17.1 \%$ compared with $9.7 \%$ in an age-matched control population. From here, it has been hypothesized that the high prevalence of androgen deficiency symptoms seen in testicular cancer patients may be due in part to chronic cancer-related fatigue which is common following systemic chemotherapy, compared to the general population.

A Norwegian study that looked at testosterone and luteinizing hormone (LH) levels following standard 3-week injection versus 2-week injection found the current standard of care TRT not to be optimal in bilateral orchiectomy patients with previous testicular cancer [26]. In this study, 43 patients had serum analysis of testosterone, LH, FSH, and sex hormonebinding globulin measured after 2 injections, 17/31 patients had subnormal testosterone levels, and 9 of the patients had highly elevated LH levels. A higher incidence of low testosterone or hypogonadism was found in 25 patients who had received TRT every 3 weeks compared to 18 patients who had received their TRT every 2 weeks [26].

\section{Conclusion}

A review of our case presents several unique factors. The above varying literature has shown our patient to have met the odds of a contralateral testicular primary development in that he did have a nonseminomatous primary, followed by a second testicular primary seminoma. Our patient exceeded the 15-year cumulative risk of contralateral metachronous testicular cancer of $1.9 \%$ versus the seemingly contradictory $5.2 \%$ cumulative risk 25 years after the first testicular germ cell tumor. With his second primary (seminoma), he presented with the common retroperitoneal landing zone site, though with an uncommon involvement of the gastrointestinal tract $(<1 \%)$ and rare incidence of involving the duodenum. This was very much likely due to the severity of size, resulting in direct invasion of the duodenum. As expected, he presented with a new onset of anemia ultimately leading to his diagnosis and presentation to our clinic.

One interesting and unanswered aspect behind this case is the question of hereditary involvement which could be addressed by a quality family history. For our patient, this will remain unanswered as he was adopted. Expanding into further publications on this matter would not apply to our case, but could lead to the current frontier of genetic susceptibility of both acquired versus hereditary risk factors. 


\section{Statement of Ethics}

The authors have no ethical conflicts to declare.

\section{Disclosure Statement}

The authors have no conflicts of interests to disclose.

\section{References}

1 Gilligan T, Beard C, Carneir B, Cost N: NCCN Guidelines Version 2.2. Standards of Testicular Cancer.

2 Kasper D, Fauci A, Hauser S, Longo D, Jameson J, Loscalzo J: Harrison's Principles of Internal Medicine, ed 19. New York, McGraw-Hill Education, 2015, Part 7: Oncology and Hematology.

3 Goljan EF: Lower urinary tract and male reproductive disorders; in Goljan EF (ed): Rapid Review Pathology, ed 4. Philadelphia, Elsevier, 2013, pp 536-539.

4 Bosl GJ, Feldman DR, et al: Cancer of the testis; in DeVita VT, Lawrence TS, Rosenberg SA (eds): DeVita, Hellman, and Rosenbergs's Cancer: Principles and Practice of Oncology, ed 8. Philadelphia, Wolters Kluwer, Lippincott Williams \& Wilkins, 2011.

5 Osterlind A: Risk of bilateral testicular germ cell cancer in Denmark: 1960-1984. J Natl Cancer Inst 1991;83:1391-1295.

6 Michaelson M, Oh W: Epidemiology of and risk factors for testicular germ cell tumors.

https://www.uptodate.com/contents/epidemiology-of-and-risk-factors-for-testicular-germ-celltumors? source=search_result\&search=epidemiology+and+risk+factors+for+testicular+germ+cell+tum ors\&selectedTitle $=1 \sim 130$.

7 Gospodarowicz M: Testicular cancer patients: considerations in long-term follow-up. Hematol Oncol Clin North Am 2008;22:245-255.

-8 Al Ani AH, Al Ani HA: Testicular seminoma metastasis to duodenum. Misdiagnosed as primary duodenal tumor. Int J Surg Case Rep 2016;25:149-152.

-9 Senadhi V, Dutta S: Testicular seminoma metastasis to the gastrointestinal tract and the necessity of surgery. J Gastrointest Cancer 2012;43:499-501.

10 Thomas JPJ: Null association between histology of first and second primary malignancies in men with bilateral testicular germ cell tumors. Am J Epidemiol 2013;178:1240-1245.

-11 Rusner C, Streller B, Stegmaier C, Trocchi P, Kuss O: Risk of second primary cancers after testicular cancer in East and West Germany: a focus on contralateral testicular cancers. Asian J Androl 2014;16:285-289.

12 Pavic M, Meeus P, Treillux I, et al: Malignant teratoma 32 years after treatment of germ cell tumor confined to testis. Urology 2006;67:846.

13 Oldenburg JM, Martin JM, Fossa SD: Late recurrence of germ cell malignancies: a population-based experience over three decades. Br J Cancer 2006;94:820-827.

14 Oldenburg J, Martin JM, Fossa SD: Late relapse of germ cell malignancies: incidence, management, and prognosis. J Clin Oncol 2006;24:5503-5511.

15 Lauro S, Righini R, Onesti CE, Pucci E, Bramini A, Marchetti P: Gastic metastasis from testicular cancer: case report and review of literature. J Gastrointest Canc 2014;45(suppl 1):S22-S24.

16 Cicin I, Ozylmaz F, Karagol H, Yalcin F, Uzunoglu S, Kaplan M: Massive upper gastrointestinal bleeding from pure metastatic choriocarinoma in patient with mixed germ cell tumor with subclinical intestinal metastasis. Urology 2009;73:443.e15-e17.

17 Chait MM, Kurtz RC, Hajdu SI: Gastrointestinal tract metastasis in patients with germ-cell tumor of the testis. Am J Dig Dis 1978;23:6549-6555.

$\checkmark 18$ Chait MM, Kartz RC, Hadju SI: Gastrointestinal tract metastasis in patients with germ-cell tumor of the testis. Am J Dig Dis 1978;23:925-928.

19 Jemal A, Siegel R, Ward E, Hao Y, Xu J, Thun MJ: Cancer statistics, 2009. CA Cancer J Clin 2009;59:225249.

20 Senadhi V, Dutta S: Testicular seminoma metastasis to the gastrointestinal tract and the necessity of surgery. J Gastrointest Cancer 2012;43:499-501.

21 Chia V, Quraishi S, Graubard B, Stancyk F, Rubertone M, Erickson R, McGlynn K: Serum testosterone concentrations and risk of testicular germ cell tumors. Cancer Prev Res 2008;1(7 Suppl):A106.

22 Sgobba C: Can your muscle-building supplements give you testicular cancer? Mens Health News. 2015. http://www.menshealth.com/health/. 


\section{Case Reports in Oncology}

\begin{tabular}{l|l}
\hline Case Rep Oncol 2017;10:832-839 \\
\hline DOI: 10.1159/000478846 & $\begin{array}{l}\text { C 2017 The Author(s). Published by S. Karger AG, Basel } \\
\text { www.karger.com/cro }\end{array}$ \\
\hline
\end{tabular}

Buck et al:: An Uncommon Presentation of a Metachronous Testicular Primary Nonseminoma and Seminoma Separated by Two Decades

23 Oldenburg J, Haugnes S, Gillessen S, Tandstad T: Long-term complications after testicular cancer treatment. 2017 Genitourinary Cancers Symposium, Alexandria, 2016.

-24 Lackner JE, Koller A, Schatzl G, Marberger M, Kratzik C: Androgen deficiency symptoms in testicular cancer survivors are associated with sexual problems but not with serum testosterone or therapy. Urology 2009;74:825-829.

25 Oree IJ, Fossa SD, Murison R, et al: Chronic cancer-related fatigue in longer-term survivors of testicular cancer. J Psychosom Res 2008;64:363-371.

-26 Fossa SD, Opjordsmoen S, Haug E: Androgen replacement and quality of life in patients treated for bilateral testosterone cancer. Eur J Cancer 1999;35980:1220-1225.
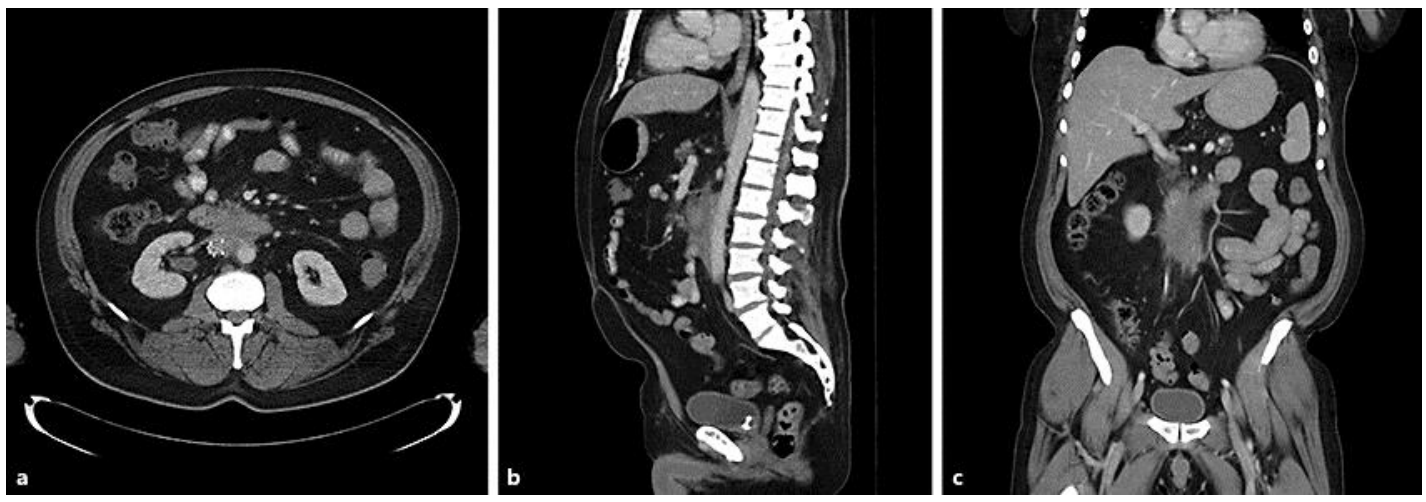

Fig. 1. Initial CT of the chest (a), abdomen (b), and pelvis (c) at presentation.
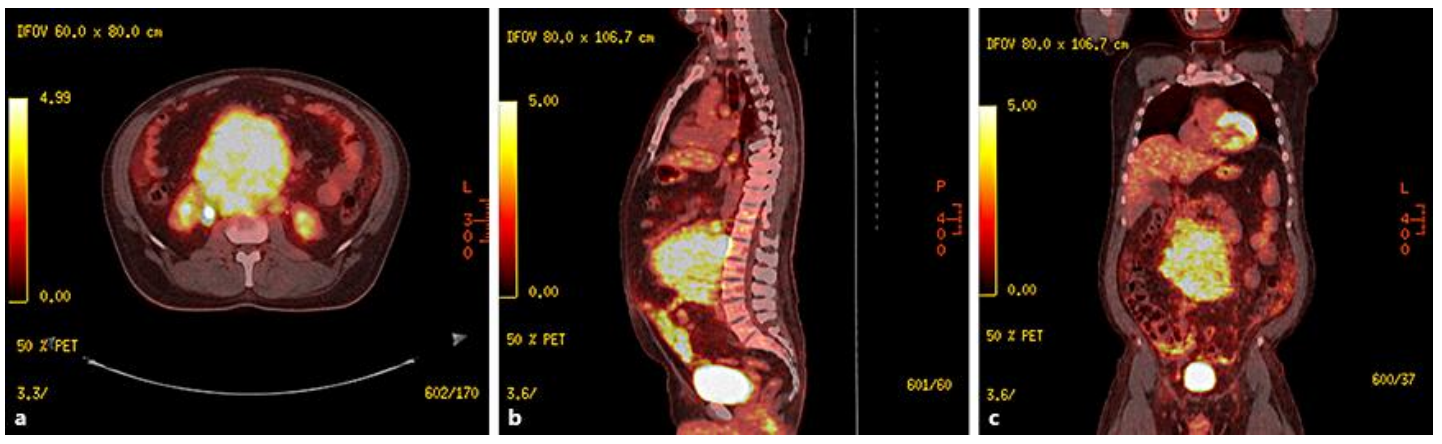

Fig. 2. Pretreatment PET scan. 


\section{Case Reports in Oncology}

www.karger.com/cro
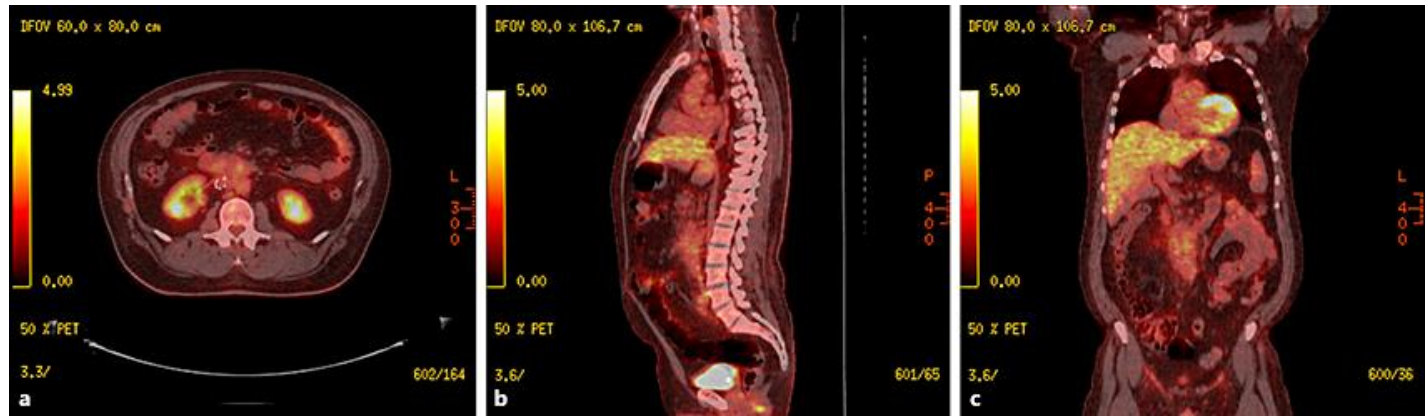

Fig. 3. PET scan 6 weeks after the last dose of chemotherapy.
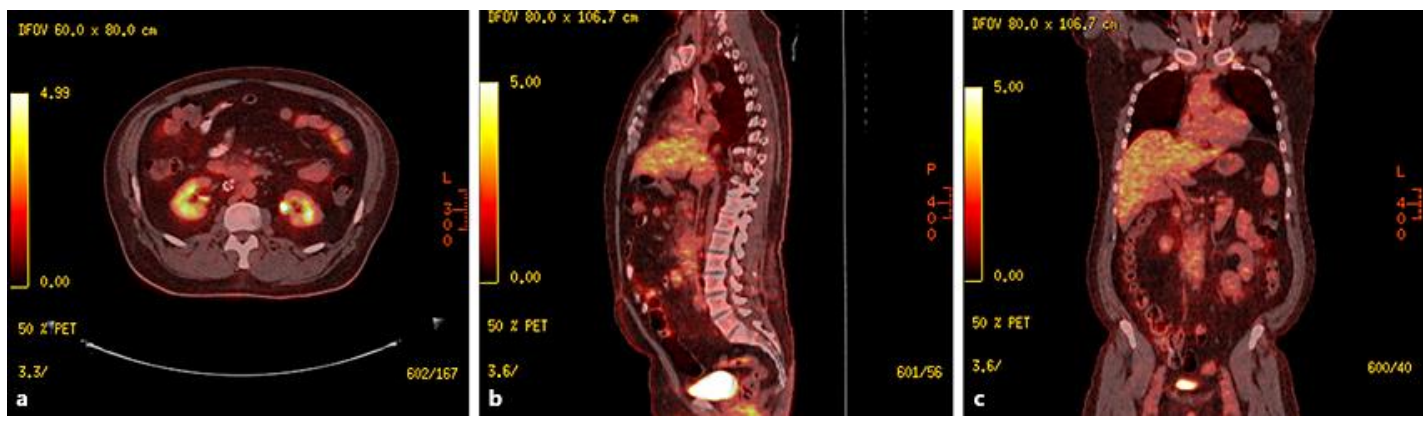

Fig. 4. Restaging PET scan 14 weeks after the last dose of chemotherapy. 